\title{
The impact of energy-saving measures on the environment
}

\author{
Botir Giyasov ${ }^{1 *}$ \\ ${ }^{1}$ Moscow State University of Civil Engineering, 129337, Yaroslavskoe shosse, 26, Moscow, Russia
}

\begin{abstract}
The Earth's biosphere has recently been increasingly exposed to pollution sources. The economic growth of the leading countries of the world contributes to the active development of artificial sources of pollution of the environment, which are formed due to the rapid economic activity of man. Human impact on the ecosystem is manifested as a result of the rapid development of urban space and transport infrastructure, as well as active energy consumption. The development of high-rise buildings of dense development in modern cities creates an unfavorable environmental situation in the residential zone. In densely built-up areas of the city, an industrial environment is formed. As a result of this, in a residential urban environment subject to the influence of anthropogenic factors, the natural heat-wind and air exchange conditions are changing. Using the buildings of the Moscow International Business Center MoscowCity as an example, the paper analyzes the causes of the concentration of harmful emissions in yard spaces and streets as a result of active energy consumption. A deep analysis of the influence of natural and artificial sources of pollution on the living environment is carried out. Energy consumption is identified as the cause of artificial pollution sources. The role of urban transport in the deterioration of the environmental situation of a modern city is assessed.
\end{abstract}

\section{Introduction}

The problem of pollution of the Earth's biosphere, and as a result, environmental degradation, has recently become increasingly important.

Rapid economic growth and development of modern cities, as a result of which the pace of development of modern buildings and structures, as well as engineering and transport infrastructure is increasing, results in serious changes in the environment.

A human being, as part of the environment, enjoys the benefits of nature and continuously interacts with all its changes. Human existence is based on the natural metabolism between man and nature. In this regard, a socially practical attitude of people towards nature has formed, the basis of which is material production. The development of the economy, contributing to the growth of productive forces leads to an increase in the mass of substances involved in economic turnover. As a result of this, the influence of man

\footnotetext{
* Corresponding author: dandyr@mail.ru
} 
on the environment and the conditions of his life is growing rapidly. Such processes lead to serious changes in the natural environment and require deep study.

In modern megacities, there is a strong deviation of the ecological balance from the required indicators. One of the main reasons is reckless consumption and destruction of biota. It is known that biota, as a set of living organisms, maintains the balance of the environment. For many centuries, the biosphere's stability was facilitated by human consumption of biota of not more than $1 \%$, and $99 \%$ was spent on stabilizing the environment. The analysis revealed that in the 20th century humanity exceeded this threshold, which led to global environmental problems. It has been established that at present the Earth's population consumes about $10 \%$ of biota production for its needs while destroying another $30 \%$, which causes significant changes in the biosphere [1,2]. In this regard, the problem of rational use and protection of the biosphere from pollution sources, in general, and its ecosystems and their components is an urgent problem of our time.

As it is known, sources of pollution, being of natural and artificial origin, are constantly growing factors in the urban environment (Diagram 1) [3]. Attempts to reduce their impact on the ecology of the environment do not give the desired effect.

The phenomena causing natural sources of pollution, as a rule, have a natural origin of a global nature and their prevention is not possible, although modern technologies make it possible to predict their intensity and time of activity. One can only assess the damage caused to the environment by these natural phenomena and propose measures to combat their consequences. As a rule, the balance of the ecology of the environment caused by some kind of natural phenomena occurs over a long period of time by self-cleaning.

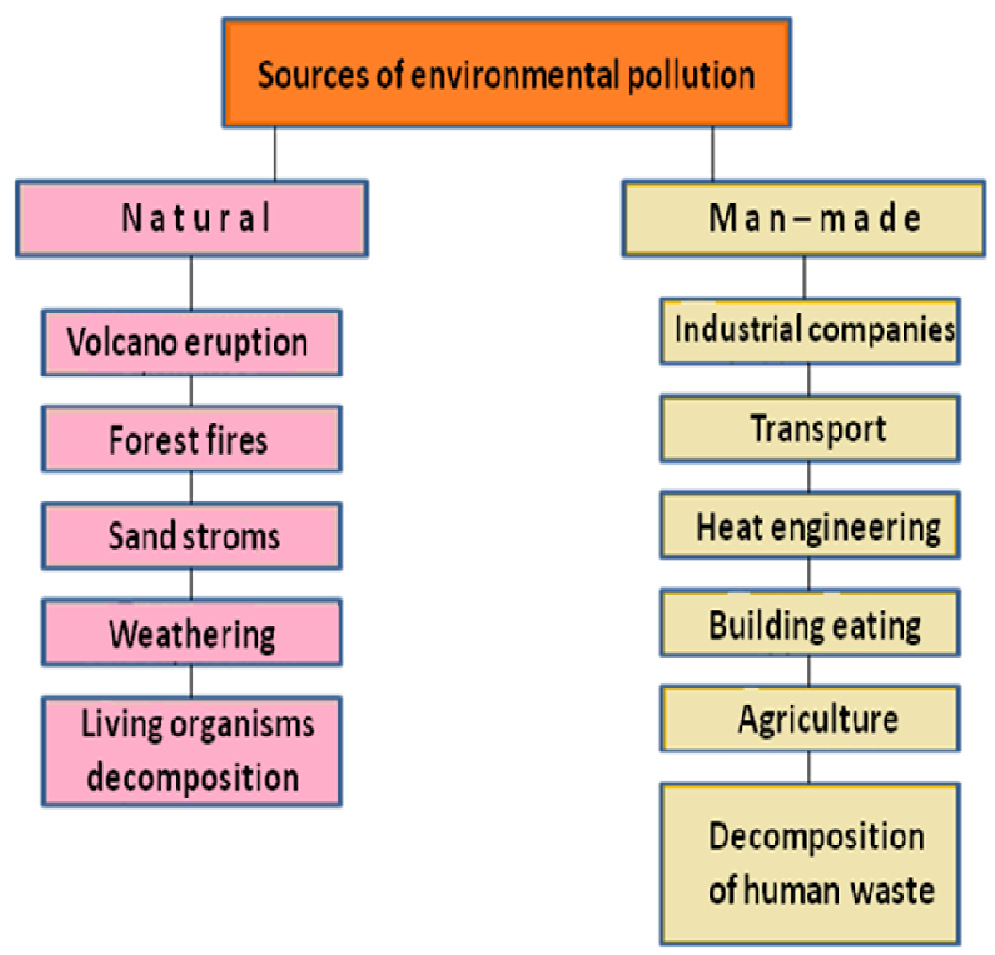

Fig. 1. Sources of environmental pollution. 
Man-made sources of pollution are of anthropogenic origin, which arose in the process of urbanization and human activities. The rapid growth of the global economy, leading to the development of large cities, industry, transport and engineering infrastructure, has led to the emergence of anthropogenic environment as a result of active energy consumption. The anthropogenic environment actively affects both the biosphere of the Earth and directly to humans. Influence on a person can be direct or indirect. As a result of direct influence, industrial or household injuries may occur. An indirect effect of the anthropogenic environment on a person occurs due to deterioration in the composition of air, the quality of water, food, and also soil changes. Thus, the artificial, man-made environment created by man, causing artificial sources of pollution, causes significant damage to the environment. [4].

It is known that the result of emissions of pollution sources as a result of energy consumption are polycyclic aromatic hydrocarbons (PAHs) - compounds consisting of many chemicals with varying degrees of carcinogenic activity. Fig. 2 shows a diagram of $\mathrm{PAH}$ environment pollution and its self-cleaning. The main artificial sources of PAH emissions should be destroyed by known factors of the natural environment. The biosphere system that starts the self-cleaning process cannot cope with the rapid growth of the negative environmental impact of artificial pollution sources.

\section{Main artificial sources of PAH emissions Known factors of PAH destruction}

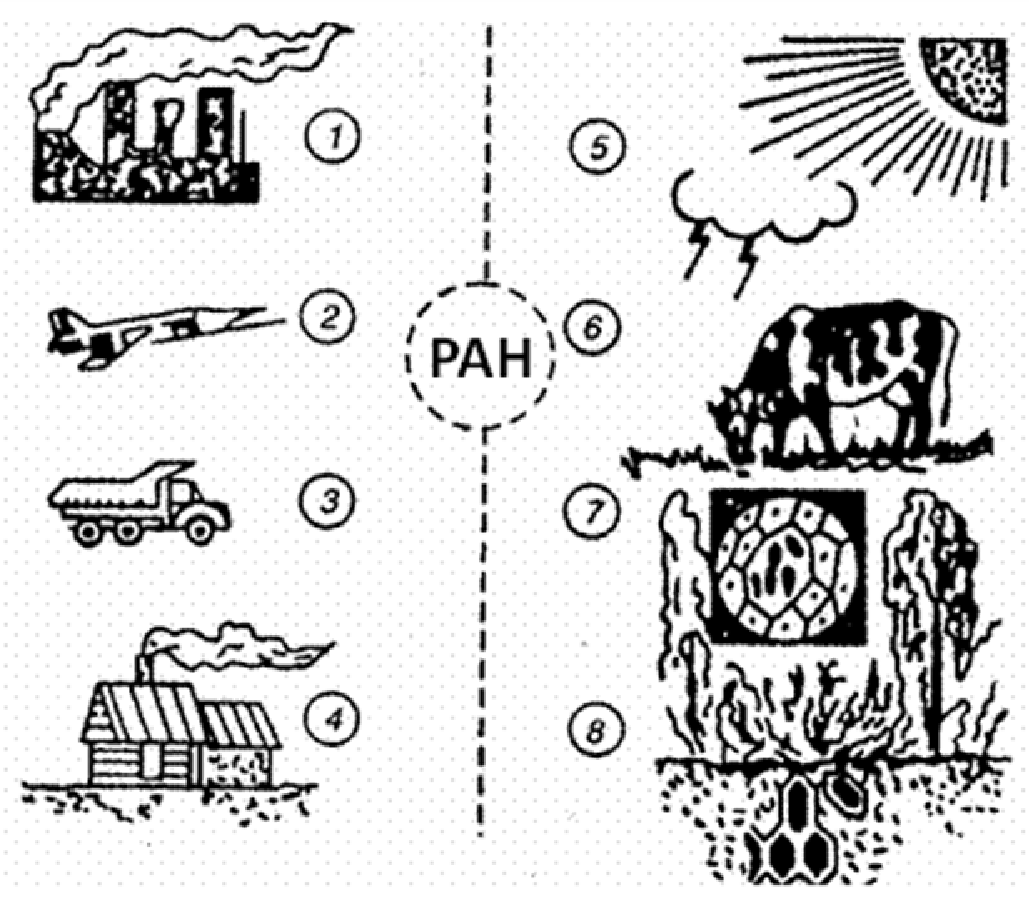

Fig. 2. Diagram of PAH environment pollution and its self-cleaning, J. Probl. Reg. Eco. 4 (2010)

Thus, the most possible measures to improve the environment is to solve the problem of optimizing the impact of anthropogenic factors on the biosphere. The anthropogenic environment, as an environment artificially created by man, can be optimized and changed by rational design decisions. The most aggressively anthropogenic environment is developing in large cities and developed megacities, where demand for energy is growing [5]. 
Modern cities are characterized by a large number of high-rise buildings, building density and a constantly evolving transport infrastructure. This is facilitated by external and internal migration, which leads to population growth in cities with the need of people for the convenience of living in a residential environment.

Modern cities are characterized by a large number of high-rise buildings, building density and a constantly evolving transport infrastructure. This is facilitated by external and internal migration, which leads to population growth in cities with the need of people for the convenience of living in a residential environment.

Residential environment, being one of the main parts of the urban environment, has features that are complex in terms of mechanism and parameters. The living environment of the largest city, mainly consisting of multi-storey high-rise buildings and modern courtyards, in the process of development changes the heat and wind regime of the area, and complicates the environmental situation. In this regard, it can be argued that not only the industrial part of the city is environmentally unfavorable, but also a residential area with dense civilian buildings [6,7].

It is obvious that with the development of the residential area, the demand for electricity generated by thermal power plants is growing. The operation of thermal power plants, as a traditional way of generating heat and electricity, using fuel in technological plants, attracts significant natural resources and has a global impact on the environment. This is due to the fact that the terrain is completely changing and the soil layers in the territory of the thermal power plant are disturbed. The released masses of heat and moisture reduce solar illumination, and a large amount of waste is thrown into reservoirs, which causes a disturbance in the balance in the ecosystem.

In addition, in the residential area of modern cities, high-rise construction mainly develops and their energy consumption increases. The complex of high-rise buildings, forming compactness, seriously affects the heat and wind conditions of the area, which violates local aerodynamics, aggravating the environmental conditions [8-10].

\section{Materials and methods}

The analysis and research of the Moscow City International Business Center revealed that the compactly located towers transformed the wind regime of the area. The rapidly developing transport and engineering infrastructure seriously aggravate the environmental situation. Due to the building density of the Moscow City business center and the activity of transport links, extensive stable zones with air stagnation arise on the territory, where wind speeds range from 0 to $1 \mathrm{~m} / \mathrm{s}$. Thus, the territory of the Moscow City Business Center created its own local climate, with impaired air aeration. Our calculation of the change in wind speed along the height of the building allowed us to assess the change in wind speed in the territory of the Moscow City Business Center.

The wind speed $V$ at a height $h$ depending on the type of terrain in the power law model is calculated by the formula [11]:

$$
V_{h}=V_{0}\left(\delta_{0} / h_{0}\right)^{\alpha}(h / \delta)^{\alpha}, m / s
$$

where $V_{h}$ is wind speed, $\mathrm{m} / \mathrm{s}$, at a height h, m, on terrain, the type of which is characterized by an exponent $\alpha$ and thickness of the boundary layer $\delta$; 
$V_{0}$ is wind speed, $\mathrm{m} / \mathrm{s}$, measured at a height $h_{0}, \mathrm{~m}$, on terrain, the type of which is characterized by an exponent $\alpha_{0}$ and thickness of the boundary layer $\delta_{0}$;

$\alpha$ is exponent depending on the type of terrain and found experimentally;

$\delta$ is thickness of the boundary layer, $\mathrm{m}$, for the considered type of terrain, the values $\alpha$ and $\delta$ are recommended in [11]: for centers of big cities $\alpha=0.33, \delta=460 \mathrm{~m}$;

$\alpha_{0}, \delta_{0}$ are exponent and thickness of the boundary layer for the area where the wind speed $V_{0}$ is fixed; as a rule, wind speeds are measured at meteorological stations located in an open area, at an altitude of 10-15 m, in which case $h_{o}=10-15 \mathrm{~m}, \alpha_{0}=0.14, \delta_{0}=270 \mathrm{~m}$.

Based on the obtained values, Figure 3 shows a graph of the correlation between the wind speed and the height of the building constructed taking into account the type of terrain.

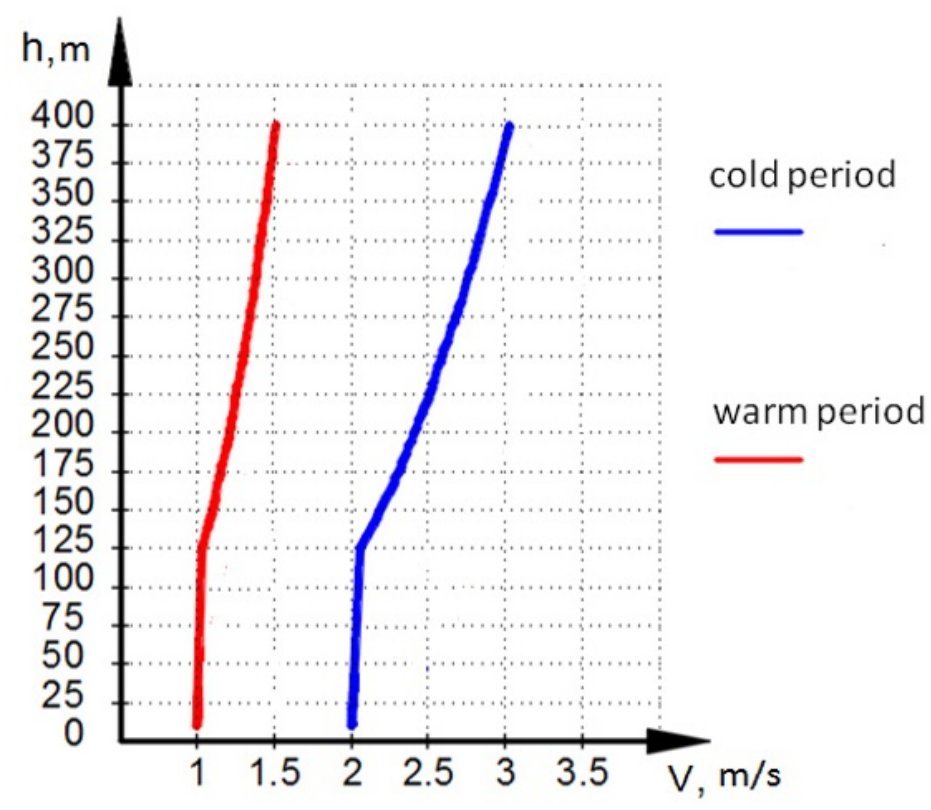

Fig. 3. The change in wind speed depending on the height in the city

The graph shows that in altitude up to $130 \mathrm{~m}$ the wind speed remains unchanged, starting from $130 \mathrm{~m}$ and above, there is a slight increase in the movement of air masses. Thus, it can be argued that dense high-rise buildings form vast and stable zones in cities, with an excess of atmospheric concentrations of pollutants from urban transport and other sources.

Urban transport is one of the main sources of environmental pollution. The main sources of energy consumption of transport are fuel and energy resources, the use of which increase the amount of emissions of harmful substances. The global demand for fuel and energy resources by the transport industry is associated with the rapid growth of the economies of the countries [12,13]. 
According to the International Energy Agency (hereinafter - IEA) in the period from 1990-2011, the transport industry has become the fastest growing sector of oil products consumption.

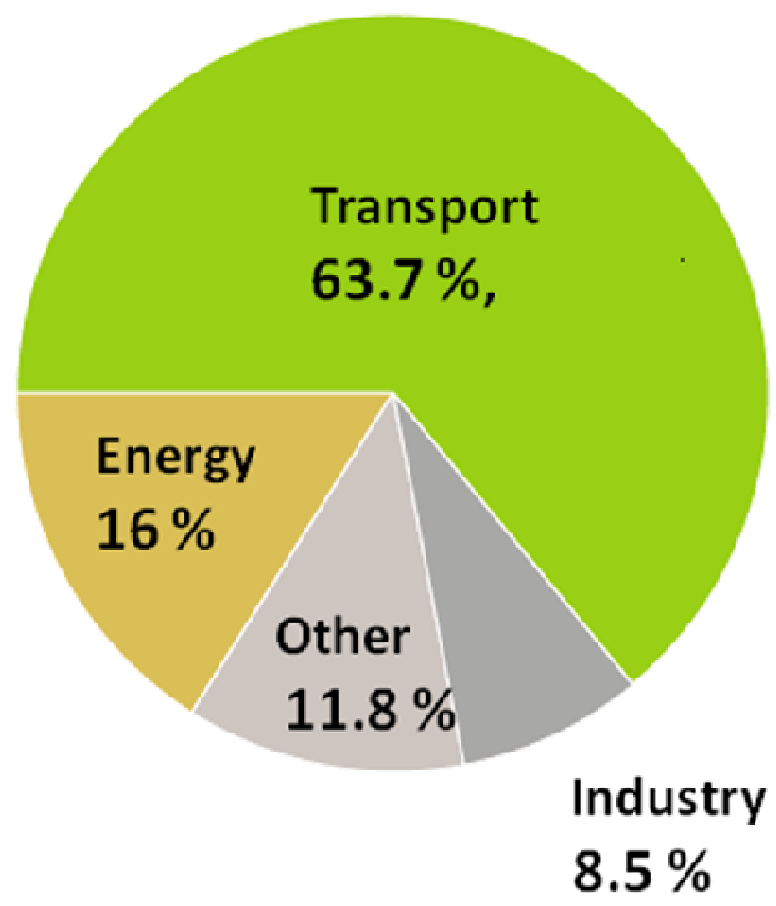

Fig.4. Oil product consumption by industry, International Energy Agency Data (2012)

As can be seen from diagram (4), in the global transport system, according to experts, $70 \%$ of the energy used is consumed by road transport, including passenger transport accounts for $50 \%$ of energy consumption. The density and activity of road transport is characteristic of urban infrastructure. In cities with developed infrastructure, the transport network forms a set of streets and transport passages served by various types of urban transport, as well as underground, ground and elevated transport lines.

International experience shows that the more roads are built, the heavier the traffic is. This leads to inefficient consumption of fuel and energy resources by land transport caused by traffic congestion. For example, in Moscow in 2005 there were about 3.5 million cars. On average, each of them, according to some estimates, spends 40-45 hours/month in traffic congestion. For an hour of engine idling, cars consumed 1 liter of fuel [14]. In this regard, it can be argued that in areas where traffic congestion is systematically generated, the concentration of harmful emissions from the use of transport is significantly increased. Therefore, to reduce the impact of harmful transport emissions on the environment, it is necessary to optimize both the energy efficiency of transport and the transport infrastructure.

One way to increase the energy efficiency of transport is energy-efficient driving. Energy-efficient driving or what is commonly called eco-driving is the observance of several basic rules by car owners, including:

1. Smooth start and smooth braking;

2. Turning off the engine in traffic congestion when the car runs at idle speed for more than 60 seconds; 
3. Compliance with the established tire pressure parameters (we want to note that world tire manufacturers are already presenting energy-efficient tires, information about them can be found on the internet);

4. Economical use of heating and air conditioning;

5. Maintaining good technical condition of the vehicle;

6. Updating the car fleet.

Compliance with these rules will reduce emissions and reduce fossil fuel consumption. To do this, it is necessary to dedicate the owners of automobile vehicles in issues of energyefficient driving [15]

Thus, it should be noted that the residential environment of modern cities is heavily affected by urbanization due to the development of high-rise construction, increased amount of urban transport and improvements in transport infrastructure.

\section{Conclusions}

1. When planning and designing buildings, on order to improve the urban environment, it is necessary to take into account the features of the built-up areas, three-dimensional design and density of future buildings affecting the aerodynamics of the area.

2.It is necessary to conduct a thorough analysis of the energy consumption of modern urban area in order to identify the causes of pollution of the residential urban environment.

3. In order to improve the environment of future urban areas and ensure optimal air exchange, competent planning of their spatial-planning structure is necessary.

4. It is important to optimize the energy efficiency of urban transport; to plan properly transport infrastructure in order to reduce the environmental impact of transport emissions. It is advisable to create car-free zones in the residential part of the city, and it is also necessary to create streets without intersections.

5.It is important to introduce a ban on through traffic in residential areas.

6. The analysis will allow assessing the impact of energy-saving measures on the environment. A person cannot influence natural disasters that contribute to the formation of natural sources of pollution, but can limit the development of artificial sources of pollution by optimizing energy conservation.

\section{References}

1.V. N. Prjahin, A. L. Bolsherotov, N. E. Rjazanova, J. Vestnik RUDN, Ser. Eco. Life Saf. 3, $72-76$ (2009)

2.B. Giyasov, I. Giyasova, MATEC Web of Conferences, 193, 01034 (2018)

3. M. Song, S. Wang, Proc. Saf. Envir. Prot. 116, 745-753 (2018)

4. Y. Dong, S. Shao, Y. Zhang, J. Clean. Prod. 234, 436-450 (2019)

5.B. Cooke, R. Lane, Re-thin. Rural-amen. Eco. Envir. Manag. Anthropoc. Eco Model. 293, 4-21 (2014)

6.C. Hamilton, A. Macintosh, N. Patrizi, S. Bastianoni, Encyclopedia of Ecology, 4, 319-326(2019)

7.B. C. Patten, Syst. Eco. Envir.Get. Sci. Right Eco. Engin. 61(A), 446-455 (2013)

8. M. A. Lokoshhenko, Abstracts 20tn All-Russian School-Conference of Young

Scientists Composition of the atmosphere. Atmospheric electricity. Climatic effects, 9-10 (2016)

9. M. Song, S. Wang, J. Clean. Prod. 242, (2020), Article 118555.

10. Ju. A. Tabunshhikov, M. M. Brodach, N. V. Shilkin, Energy efficient buildings, (2003) 
11. X. Guo, Q. Zhu, L. Lv, J. Chu, J. Wu, J. Clean. Prod. 140, 2017, 1313-1321 (2017)

12. J.J. Jia, J.H. Xu, Y. Fan, Renew. Sustain. Ener. Rev. 95, 56-73 (2018)

13. C. Xie, M. Bai, X. Wang, Ener. Pol. 123, 525-532 (2018)

14. P. Moriarty, D. Honnery, Ener. Pol. 46, 1-3 (2012) 